Viso - Cadernos de estética aplicada Revista eletrônica de estética

ISSN 1981-4062

No 19, jul-dez/2016

http://www.revistaviso.com.br/
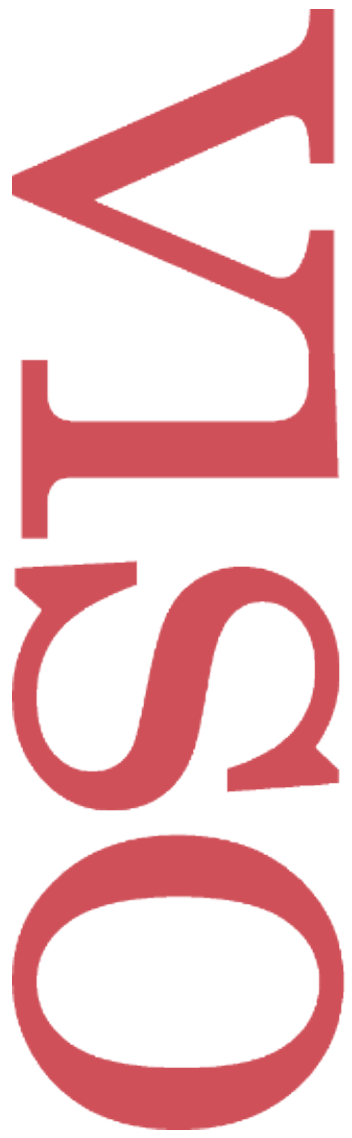

\title{
Quem, afinal, a arte espelha? Debora Pazetto
}




\section{RESUMO}

Quem, afinal, a arte espelha?

Este breve ensaio foi elaborado como desenvolvimento de algumas questões levantadas por Pedro Süssekind em seu artigo Arte como espelho. O autor analisa a ideia dantiana de que a arte é um espelho no qual, em um sentido, os espectadores podem ver sua própria face e, em outro sentido, podem visualizar certas características históricas do público para o qual a obra foi feita, pois ela é também um espelho do contexto histórico que tornou possível sua criação. Junto com essa qualidade epistemológica da arte, surge uma qualidade prática ou ética: o potencial transformador da arte, que pode levar um indivíduo a "mudar de vida". A partir desses apontamentos, proponho a questão: em que medida a arte contemporânea, inserida nos grandes circuitos do mundo da arte, é capaz de espelhar e, portanto, de interpelar significativamente os sujeitos e as sociedades?

Palavras-chave: arte contemporânea - mundo da arte - museu - autoconhecimento sociedade

\section{ABSTRACT}

\section{Who Does Art Mirror in the End?}

This brief essay is an answer to some issues raised by Pedro Süssekind in his paper Art as a mirror. The author analyses Danto's idea that art is a mirror in which, in a sense, the spectators can see their own face and, in another sense, they can visualize some historical characteristics of the public for whom the artwork was intended, for it also is a mirror of the historical context that enabled its creation. Allied with this epistemological quality of art, a practical or ethical quality emerges: the transforming potential of art, which can lead people to change their life. Based on these remarks, I propose the question: to what extent can contemporary art, inside the great circuits of the artworld, reflect and, therefore, significantly interpellate individuals and societies?

Keywords: contemporary art - artworld - museum - self-knowledge - society 
PAZETTO, D. "Quem, afinal a arte espelha?". In: Viso: Cadernos de estética aplicada, v. X, n. 19 (jul-dez/2016), pp. 153-161.

DOI: $10.22409 / 1981-4062 / v 19 i / 237$

Aprovado: 14.10.2016. Publicado: 28.12.2016.

(C) 2016 Debora Pazetto. Esse documento é distribuído nos termos da licença Creative Commons Atribuição-NãoComercial 4.0 Internacional (CC-BY-NC), que permite, exceto para fins comerciais, copiar e redistribuir o material em qualquer formato ou meio, bem como remixá-lo, transformá-lo ou criar a partir dele, desde que seja dado o devido crédito e indicada a licença sob a qual ele foi originalmente publicado.

Licença: http://creativecommons.org/licenses/by-nc/4.0/deed.pt_BR

Accepted: 14.10.2016. Published: 28.12.2016.

(C) 2016 Debora Pazetto. This document is distributed under the terms of a Creative Commons Attribution-NonCommercial 4.0 International license (CC-BY-NC) which allows, except for commercial purposes, to copy and redistribute the material in any medium or format and to remix, transform, and build upon the material, provided the original work is properly cited and states its license.

License: http://creativecommons.org/licenses/by-nc/4.0/ 
A partir de alguns apontamentos de Danto, o texto Arte como espelho, de Pedro Süssekind, maneja diversas camadas de especularidade na experiência artística. Inspirado no retrato de Martin Gayford pintado por Lucian Freud, o autor sofistica a relação de espelhamento entre o pintor e o modelo, na medida em que o modelo, crítico de arte, observa o pintor enquanto é observado, e ambos podem, portanto, observar-se observando, observar-se sendo observados, observar-se observando-se ser observados e, assim, ao infinito. O exemplo é denso: nele, a pintura não é um espelho imitando a realidade, sem lhe acrescentar qualquer coisa, como na concepção platônica; também não é simplesmente um espelho anteposto a um sujeito, que pode, portanto, ver algo que ele não veria na realidade - sua própria face - como Danto menciona em um primeiro momento, ao tratar de Hamlet; trata-se de um espelho na frente de outro, de infinitos espelhos espelhados. Nessa situação, além do complexo da especularidade mútua, há a impressionante manifestação de algo que não existe na realidade, e que não poderia ser imitado: uma imagem sensível do infinito.

Süssekind ainda acrescenta um terceiro componente no esquema ao considerar que, tratando-se da produção de uma pintura e de um livro, os espelhamentos estendem-se aos espectadores e leitores, que podem não apenas se identificar com a imagem ou com o texto, mas também criar novas relações interpretativas ao ver a imagem depois de ler o texto ou ao ler o texto depois de ver a imagem - possibilidades que também podem se multiplicar infinitamente, sobretudo se considerarmos a pluralidade de espectadores e leitores possíveis para cada um desses elementos. Vale lembrar de Moscarda, o personagem principal de Pirandello em Um, nenhum e cem mil ${ }^{1}$, enlouquecido ao perceber que era uma pessoa diferente para cada pessoa que o conhecia, e que uma relação entre duas pessoas na verdade é uma relação entre quatro, oito, dezesseis, e assim por diante. Do mesmo modo, não apenas cada espectador tem uma relação singular com cada obra de arte, mas a relação entre uma única obra e um espectador, do ponto de vista da materialidade, é uma relação entre dois elementos, contudo, do ponto de vista da criação de imagens, identificações e interpretações, é potencialmente infinita.

Acredito que é nesse sentido que, em Após o fim da arte, Danto afirma que "sempre voltamos às grandes obras: não porque nelas vemos algo novo a cada vez, mas porque esperamos que elas nos ajudem a ver algo novo em nós mesmos". ${ }^{2}$ Essa frase, publicada 33 anos após a primeira aparição da metáfora do espelho na obra de Danto, retoma uma ideia que é central no texto de Süssekind (naturalmente, a ideia que este meu texto reflete como central no seu, pois a relação teórica também não deixa de ser um tipo de espelhamento, e o autor poderá identificar-se com a imagem do seu texto no espelho do meu, ou indignar-se, como Moscarda). Trata-se da ideia de que a arte é um espelho no qual, em um sentido, cada espectador pode ver sua própria face - em $A$ transfiguração do lugar-comum, a explicação para isso é construída principalmente em torno da ideia de que a interpretação da obra é considerada uma parte essencial da mesma - e, em outro sentido, cada espectador, em qualquer época, pode visualizar certos atributos históricos do público para o qual a obra foi feita, pois ela é também um 
espelho do contexto histórico que tornou possível sua criação. No primeiro sentido, a arte pode ser, em geral, um instrumento de autoconhecimento. No segundo sentido, pode ser instrumento de conhecimento histórico ou, no caso da arte contemporânea, de autoconhecimento social e coletivo, que "pode servir para capturar a consciência de nossos reis". ${ }^{3}$ Junto com essa qualidade epistemológica da arte, surge uma qualidade mais prática, ou ética, que Süssekind indica no final de seu texto: o potencial transformador da arte, tema que Danto não desenvolve na Transfiguração.

Cito Süssekind citando Danto citando Rilke referenciando Rodin: "pois ali ponto não há / Que não te mire". Os versos de Rilke atribuem um olhar ao torso de Apolo, esculpido por Rodin, no qual o poeta se vê refletido. Danto vê, refletida nesses versos, a ideia de que a arte é uma imagem especular, a qual interpela o sujeito que a observa. Süssekind conecta essa especularidade, que surge na teoria de Danto, via Hamlet e Rilke, na Transfiguração, com uma ênfase que aparece anos mais tarde, em O abuso da beleza, relativamente ao mesmo poema: "força é mudares de vida". A exigência final de mudar de vida é pensada, portanto, como uma consequência do autoconhecimento possivelmente avassalador produzido pela reflexividade da arte. Gostaria de acrescentar que esse potencial transformador foi abordado por Danto no principal livro que escreveu entre a Transfiguração e $O$ abuso da beleza, intitulado Após o fim da arte: a arte contemporânea e os limites da história, em um capítulo muitas vezes esquecido, o qual tem o exótico título de "Museus e milhões de sedentos". Perguntando-se por que, afinal, frequentamos instituições e espaços dedicados à arte, o autor faz uma defesa do potencial, inerente às experiências com obras de arte, de transformar o pensamento, a vida ou ponto de vista das pessoas. Ademais, fundamenta nessa possibilidade transformadora uma justificativa para a existência de instituições e políticas estatais de apoio à arte. ${ }^{4}$ Mesmo que não haja qualquer tipo de garantia de que a arte provocará experiências significativas para os sujeitos, seria a aposta nessa possibilidade, e em sua relevância social, o que justificaria o financiamento público de instituições culturais.

"Mudar de vida" não acontece em uma experiência rotineira ou trivial com obras de arte, mas no encontro com a arte em um contexto subjetivamente profundo, que provoca algum ponto de ruptura na vida do indivíduo ou da coletividade. Danto afirma que obras de arte são fulcros de significado, são fontes de sentido para a vida humana. ${ }^{5}$ Trata-se de uma retomada da primeira condição necessária para que algo seja arte, desenvolvida na ontologia da Transfiguração, isto é, a exigência de que obras de arte sejam sobre alguma coisa, tenham um conteúdo, um significado [aboutness]. A retomada ocorre, no entanto, de modo qualificado: a arte não pode ter qualquer significado, uma vez que placas de trânsito e mapas também têm, mas um significado capaz de mudar a vida de alguém. Essa experiência transformadora acontece, de acordo com a lógica argumentativa do texto de Süssekind, quando há, primeiramente, uma relação de espelhamento, na qual o sujeito percebe a si mesmo por meio da obra. $O$ autoconhecimento, ou o autorreconhecimento, digamos, gerado em uma vivência significativa com a arte seria capaz de disparar alguma espécie de transformação individual ou social. 
A questão é: como e em que medida obras de arte são capazes de espelhar e, portanto, de interpelar significativamente certos sujeitos e coletividades? Retomo a citação de $O$ abuso da beleza feita por Süssekind, referente à análise crítica dantiana da pintura $O$ casamento de Peleu e Tétis: "e o que significa a história dessa última refeição para nós, sentados em nosso castelo, no topo do mundo, aproveitando as boas coisas da vida arte, vinho, coisas saborosas para comer e a companhia uns dos outros?". ${ }^{6}$ Süssekind sublinha que, nessa passagem, o autor remete-se aos espectadores atuais do mundo da arte, como nós e como ele próprio: "observadores que conhecem seu Ovídio, apreciam a arte maneirista", etc. Essa pintura é, afinal, uma obra de arte transformadora? A resposta de Danto, típica de sua abordagem como crítico de arte, vai na direção do destaque de elementos estéticos e conceituais que expliquem o contexto da obra e aprofundem seu significado. Além disso, ele observa que, para capturar esse significado, é preciso ver a obra como algo a mais do que uma simples caracterização da aristocracia holandesa da época. Pois bem, pergunto: em que medida a arte contemporânea, inserida nos grandes circuitos do mundo da arte, vai além da caracterização de uma aristocracia intelectual e cultural que conhece Ovídio e arte maneirista, aproveita as coisas boas da vida e a companhia uns dos outros?

Por que, afinal, museus, galerias e teatros são tão pouco frequentados pela grande massa da população? Será que esse formato expositivo e, em geral, as obras assim expostas refletem de algum modo essas identidades? Se, como Danto supõe, as pessoas têm sede de sentido, sede de arte e de cultura, por que muitos museus são amplos templos vazios, ou são visitados majoritariamente com fins turísticos, ou então sempre pela mesma elite culta? ${ }^{7}$ Essas considerações tornam as instituições artísticas vulneráveis a um tipo de crítica social: elas não oferecem aquilo que desejam milhões de pessoas, com sede de arte, de autoconhecimento, de experiências transformadoras. Provavelmente a arte de que estão sedentos não é aquela que as instituições costumam proporcionar, mas uma que faça sentido em suas vidas, em suas comunidades, que dialogue com suas experiências cotidianas.

O problema é que, em geral, os artistas, críticos, curadores, galeristas e administradores do mundo da arte formam círculos herméticos e usam linguagens que parecem esotéricas do ponto de vista do grande público. Hoje, o mundo da arte é dirigido principalmente por um mercado que movimenta bilhões de dólares, por instituições culturais públicas, privadas ou mistas, e por leis de incentivo à cultura. $\mathrm{O}$ acesso público a esse tipo de arte é condicionado por sua exposição e divulgação (nem sempre gratuitas), isto é, por todos os métodos institucionais que o viabilizam. De modo que devemos nos preocupar com a possibilidade de uma relação profunda e significativa com a arte diante de tantas evidências de que o mundo da arte torna-se cada vez mais dependente da estrutura econômica do mercado de obras e de políticas de consumo cultural. A mercantilização da arte determina não apenas o sistema elitizado de compra e venda de obras, mas também o circuito de exposições, mesmo em museus e instituições públicas. Sublinho, particularmente, o fenômeno que os investidores chamam de 
"alavanca de valor": as obras de um artista contemporâneo no começo da carreira têm certo preço, e, para valorizá-lo, o investidor que compra sua obra agencia seus contratos com galerias, fomenta sua participação em exposições individuais, em catálogos, no acervo de museus, etc., para que o preço de suas obras aumente.

Assim, se o desejo humano por experiências significativas e transformadoras é o que justifica as instituições e políticas públicas de apoio à arte, é preciso fazer uma crítica à reclusão do mundo da arte e sua costumeira indiferença a respeito da possibilidade de assimilação significativa daquilo que este identifica como arte contemporânea. É claro que experiências transformadoras com a arte podem acontecer fora de museus, palcos, bibliotecas, cinemas, galerias e teatros - felizmente, as ruas e os espaços coletivos alternativos têm sido cada vez mais explorados por artistas. Destaco o enorme conjunto de indivíduos e coletivos que trabalha contra a lógica do capitalismo cultural, em prol da manutenção de espaços e eventos relativamente livres para a produção de obras de arte. Há no Brasil, desde a década de setenta, um grande número de coletivos e de espaços autônomos ou autogestionados de criação e exposição de arte contemporânea, que mantêm um caráter de resistência aos mecanismos estatais de veiculação da arte. ${ }^{8}$ Há também muitos espaços e projetos que, embora contem com apoio institucional, conseguem manter uma produção livre ou subversiva ou popular. Além disso, há outras formas de exposição, como websites pessoais, redes sociais, panfletos, zinis, microcircuitos alternativos, publicações independentes, discursos, grafites, intervenções urbanas, performances, apresentações musicais e teatrais em espaços públicos da cidade, e assim por diante.

Mesmo no contexto institucional, promove-se um tipo de arte pública e/ou socialmente engajada, como construções de monumentos artísticos em praças e apresentações de dança, música e teatro em comunidades carentes ou periféricas. Tais estratégias colocam obras de arte à disposição do grande público. No entanto, concordo com a afirmação de Danto de que elas são, em alguma medida, impositivas, uma vez que condicionam as comunidades a reagirem a uma arte alheia a sua realidade, na qual uma "curadoria" determina o que pode ou deve ser apreciado: "especialistas em arte que conhecem, como o público em geral não conhece, o que é bom e o que não é". ${ }^{9}$ Semelhantes projetos, que costumo chamar de "colonização estética", não são mal intencionados, mas são provavelmente inconscientes do jogo de poder (saber-poder) que há por trás dessa atitude. Danto diferencia esse tipo de "arte pública" de uma "arte do público", que pode ser construída de duas maneiras: ou bem se concede ao público mais expressão e escolha relativamente à arte com a qual tem de conviver em espaços extramuseológicos, ou bem se transforma o público em seu próprio artista. A primeira opção autonomiza o público ao menos enquanto espectador, capaz de participar ativamente da arte como corpo consultivo com poder de decisão sobre suas preferências e desejos. A segunda opção, mais radical, incentiva que obras de arte sejam propostas nas, para e pelas diferentes comunidades, as quais podem ser definidas ao longo de 
linhas sociais, regionais, raciais, econômicas, históricas, étnicas, geográficas, sexuais, religiosas, e assim por diante.

Não se trata de tribalizar obras de arte, mas de criar opções para que diferentes pessoas, em diferentes condições, sintam-se refletidas na arte, sintam que ela faz parte de suas vidas. O reconhecimento da arte com base na comunidade, de acordo com Danto, surge a partir "de certas teorias políticas emancipadoras que sustentavam, como um de seus corolários programáticos, que grupos de indivíduos, não encontrando sentido na arte dos museus, não deveriam ser privados dos significados que a arte poderia conferir a suas vidas". ${ }^{10}$ Evidentemente, isso não significa que relações de especularidade com a arte estão restritas por classe, gênero, raça e afins. As experiências que nos tocam profundamente e mudam nosso modo de habitar o mundo podem acontecer, de modo imprevisível, com qualquer tipo de arte - um homem branco pode ver a si mesmo, talvez por ruptura e inversão, através da obra de uma feminista negra e ser, com isso, impelido a "mudar de vida", assim como uma pintura de Lucian Freud pode, eventualmente, provocar uma experiência potente para um índio maxakali ou para qualquer indivíduo completamente distanciado da alta cultura ocidental. A arte, a princípio, pertence a todos e dirige-se a todos. Na verdade, é justamente disso que se trata: de inclusão de outras vivências e perspectivas, de ampliação de contextos produtivos, de colaboração criativa.

Se a arte é valorizada, incentivada e gerida pela administração pública não apenas porque ela é um bem de mercado, mas porque é uma "dimensão simbólica inerente a todos os seres humanos" e "um direito básico do cidadão" - como lemos no website do MinC - , é preciso que a arte produzida nas regiões periféricas e nas comunidades tradicionais, nas culturas de matrizes africanas, indígenas, latino-americanas, nos movimentos feministas e LGBTIQ receba iguais reconhecimento e visibilidade que a arte produzida pelo homem branco de classe média ou alta. Se a arte é estimada pelo seu potencial cognitivo, reflexivo e transformador, é preciso que o mundo da arte - tanto nos espaços extramuseológicos quanto nos museus, centros culturais, cinemas, teatros, galerias e periódicos - deixe de ser o espaço privilegiado de uma aristocracia intelectual e cultural eurocêntrica ou estadunidense, branca, masculina e heteronormativa, que senta em seu castelo, no topo do mundo, e aprecia sua arte, seu vinho, coisas saborosas para comer e a companhia uns dos outros. Penso que a especularidade da arte produz autoconhecimento não apenas porque o sujeito se reconhece na obra, mas também porque, através da obra, percebe no artista um olhar que o reconhece. Como na peça de Shakespeare, na qual "Cláudio - espectador que reconhece seu reflexo identifica o criador da peça, Hamlet, como alguém consciente do que ele realmente é" ${ }^{11}$, como o Moscarda de Pirandello, como o voyeur de Sartre, como o público do Metropolitan ou do Pompidou, que percebe, no retrato de Martin Gayford pintado por Lucian Freud, "uma projeção de sua própria imagem, de sua curiosidade a respeito da pintura, de seu próprio olhar que busca entender o significado daquele quadro". ${ }^{12}$ 
Assim, se obras de arte são espelhos nos quais, além de sua própria face, cada espectador pode visualizar certos atributos sociais e históricos do público para o qual a obra foi feita, é preciso notar que a arte contemporânea inserida nos circuitos oficiais reflete uma sociedade elitizada, que enaltece a pintura a óleo, a escultura em mármore, a arte conceitual, a sofisticação formal, que vende por doze milhões de dólares um tubarão em uma tina de formol, mas que recusa significância ao rap, ao funk, ao grafite, à pichação e à dança do passinho. Süssekind conclui seu texto afirmando que o poema de Rilke, duplamente citado por Danto, exprime "a experiência de como uma obra de arte é capaz de abalar e pôr em xeque seu espectador, de dirigir a ele uma indagação sobre o que ele mesmo é ou pode ser". ${ }^{13}$ Desse modo, se podemos ver na arte contemporânea nossa própria face e adquirir o autoconhecimento coletivo de uma sociedade que guarda certas obras de arte dentro de palácios de acesso restrito e esconde outras embaixo de viadutos, força é mudarmos de vida.

\section{bibliografia complementar}

DANTO, A. A transfiguração do lugar comum. Tradução de Vera Pereira. São Paulo: Cosac Naify, 2010.

O descredenciamento filosófico da arte. Tradução de Rodrigo Duarte. Belo Horizonte: Autêntica Editora, 2014.

The Abuse of Beauty. The Paul Carus Lectures, 21, 2003.

GAYFORD, M. Man with a Blue Scarf. Londres: Thames \& Hudson, 2010.

\section{* Debora Pazetto é professora do CEFET/MG.}

${ }^{1}$ PIRANDELLO, L. Um, nenhum e cem mil. Tradução de Mauricio Santana Dias. São Paulo: Cosac Naify, 2001.

2 DANTO, A. Após o fim da arte: A arte contemporânea e os limites da história. Tradução de Saulo Krieger. São Paulo: Odysseus Editora, 2006, p. 199.

${ }^{3}$ Idem. "O mundo da arte". Tradução de Rodrigo Duarte. Ib: Artefilosofia, n. 1 (2006), p. 25.

${ }^{4}$ Idem. Após o fim da arte. Op. cit., p. 199.

${ }^{5}$ Ibidem. p. 211.

${ }^{6}$ Idem. O abuso da beleza. Tradução de Pedro Süssekind. São Paulo: Martins Fontes, 2015, p. 165.

${ }^{7}$ Idem. Após o fim da arte. Op. cit., pp. 196; 197.

${ }^{8}$ NUNES, K. Espaços autônomos de arte contemporânea. Rio e Janeiro: Circuito, 2013.

${ }^{9}$ DANTO, A. Após o fim da arte. Op. cit., p. 202.

${ }^{10}$ Ibidem, p. 201.

${ }^{11}$ SUSSEKIND, P. Arte como espelho. Texto apresentado durante o 80 Encontro do GT de Estética da ANPOF, 2016. 
12 Ibidem.

${ }^{13}$ Ibidem. 